\title{
Los derechos sociales en la Constitución Española
}

\section{Gonzalo José Carbonell Aparici}

Red Europea de Vida Independiente (ENIL)

maitreya.gonzalo@gmail.com
Los derechos sociales son considerados mayoritariamente en la Constitución Española como principios rectores de política social, supeditados a la economía presupuestaria, en clara diferencia con los derechos civiles. Esta orientación se basa en unos pactos internacionales que han dado pie a una praxis generalizada de ralentización que han acabado en la práctica con el Estado social, dentro y fuera de España. Este artículo pretende concienciar sobre la necesidad de acabar con esta diferencia entre unos derechos y otros, abogando por una profunda reforma de nuestra Constitución, en lo referente a la distribución de garantías del artículo 53. Pero tal reforma solo cobra sentido si también se toma conciencia de su necesidad a nivel internacional, como causa última de la brecha social que sufren todas las naciones a escala mundial.

\section{Palabras Clave:}

Derecho social, estado de derecho, igualdad, economía social, tratados internacionales, constitución nacional. 


\section{Introducción}

Si bien podemos considerar la historia como un continuum en la creación de derechos (Bobbio, 1991), con grandes altibajos y diferencias territoriales, en los últimos decenios estamos asistiendo de modo creciente a un descontento generalizado con referencia al disfrute real de estos derechos, por falta de garantías suficientes dispensadas en los diferentes Estados. La globalización tecnológica ha permitido que hoy los ciudadanos de cualquier parte del mundo, incluso en las zonas menos desarrolladas del planeta, tengan noticia de lo que sucede a miles de kilómetros. Esto incluye el conocimiento de las muy diversas protestas que los diferentes pueblos elevan ante sus gobiernos y ante el resto del mundo por la falta de respeto en lo que consideran sus derechos. Estos derechos pueden girar en torno a todo lo que conlleva una vida más digna en una sociedad concreta, pero también a todos los derechos humanos reconocidos para todos, incluido el respeto por el medio ambiente.

A nuestro modo de ver, esta situación se debe a dos factores fundamentales:

a. Por un lado, al decaimiento generalizado del Estado social, surgido en su momento como medio de suavizar las diferencias entre el nivel de vida de las diferentes clases sociales.

b. Por otro, al progresivo aceleramiento del cambio climático a causa del desequilibrio ecológico, provocado por el modo de vida humano, augurando grandes desastres y la posibilidad de la extinción de la vida misma.

Estos dos factores sirven para acentuar la incongruencia esencial del sistema económico en el que se apoya la sociedad: la producción y el consumo capitalistas, que, aunque quizá ideados en beneficio de una vida más cómoda, han traído sin embargo una brecha entre ricos y pobres cada vez más profunda y asimétrica, a la vez que un daño, quizá ya irreversible, a todo el ecosistema. Las protestas, pues, tienen hoy un sentido más profundo que en épocas pasadas en los grupos más desfavorecidos, puesto que somos, por un lado, más conscientes de los derechos reconocidos en tratados internacionales y en las constituciones democráticas, pero, por otro lado, sabemos que la causa del desequilibrio y la injusticia legal se debe más a la acción irresponsable del sistema económico que a la evolución natural, también en el plano sociológico.

Esto trae como consecuencia que la mayoría de las personas se ven sometidas a condiciones de vida reconocidas como injustas por los mismos pactos sociales logrados, que sucumben bajo la presión de grupos económicos de poder, y ya no pueden obviarse por más tiempo. Penalizar la ayuda humanitaria debida a los náufragos del Mediterráneo o el comercio de armas entre naciones son dos muestras de que ni siquiera se respetan las formas de mera apariencia en la defensa de un derecho humano tan fundamental como la vida. Está comprobado que solo protestando no se consigue mucho. Esto ya se vio en el pasado, cuando los grandes conflictos sociales se resolvieron con revoluciones sangrientas. Hoy, al menos en el primer mundo, nos consideramos demasiado civilizados para eso, mientras observamos imperturbables las atrocidades del Tercer Mundo y mantenemos la falsa apariencia de bienestar en nuestros entornos. Por eso nos parece del todo necesario que se replantee a fondo una revisión de nuestro derecho constitucional, pero también a nivel internacional.

\section{Revisión del derecho}

\subsection{Derecho internacional}

El camino hacia un derecho internacional operativo se inició con el Estatuto de la Corte Internacional de Justicia incluida en la Carta de las Naciones Unidas que firmaron cincuenta y un países en 1945, para no repetir las atrocidades cometidas durante las dos grandes guerras. Esta primera carta se completó en 1948 con la Declaración Universal de los Derechos Humanos y posteriormente, en 1966, con el Pacto Internacional de Derechos Económicos, Sociales y Culturales, por un lado, y el Pacto Internacional de Derechos Civiles y Políticos por otro. Al conjunto de estos documentos se le conoce como Carta Internacional de Derechos Humanos. A nosotros nos interesa detenernos en los dos pactos porque establecen distinciones entre unos derechos y otros que, a nuestro modo de ver, hoy han perdido su sentido y, lo que es peor, están teniendo consecuencias negativas para la ciudadanía.

\subsubsection{Pacto internacional de derechos civiles y políticos $^{1}$}

Los derechos de este pacto se derivan de la dignidad inherente a la persona humana, según se indica en su preámbulo, en el contexto de los derechos humanos. Damos una simple enumeración de los derechos contenidos expresamente, sin entrar en matices de desarrollo que suponemos conocidos: derecho a la vida (aun aceptando la pena de muerte legal); derecho a no ser torturado o maltratado; abolición de la esclavitud o servidumbre; derecho a la libertad y a la seguridad; trato digno a los presos; derecho a no ser encarcelado por el mero hecho de no poder cumplir un contrato; derecho a libre circulación; derecho del extranjero a ser expulsado solo por razones legales o de seguridad; derecho a la igualdad ante la ley; derecho a no ser condenado por actos que en su momento no eran delito; derecho al reconocimiento de personalidad jurídica; derecho a la protección de la vida privada; derecho a la libertad de pensamiento, conciencia, religión y opinión (exceptuando la incitación al odio); prohibición de

\footnotetext{
1 https://www.ohchr.org/SP/Professionallnterest/Pages/CCPR.
} 
cualquier propaganda de guerra o incitación al odio; derecho a reunión pacífica; derecho de asociación; derecho a formar libremente una familia; derecho de los niños a protección; derecho a la participación ciudadana; derecho de igualdad en las minorías.

A continuación, se establece un largo articulado sobre el Comité de Derechos Humanos, cuya finalidad es procurar que en cada Estado parte se observen los derechos pactados.

\subsubsection{Pacto Internacional de Derechos Económicos, Sociales y Culturales ${ }^{2}$}

Este pacto se apoya igualmente en la dignidad inherente a las personas y nombra expresamente los siguientes derechos: derecho al trabajo en condiciones de equidad, seguridad y satisfactorias; derecho a sindicación y huelga; derecho a la Seguridad Social; derecho a formar libremente una familia; derecho a un nivel de vida adecuado y protegido contra el hambre; derecho a la salud física y mental al más alto nivel; derecho a la educación; derecho a participación. Se indica por último que los Estados parte deben enviar anualmente un informe a las Naciones Unidas sobre las medidas que se han tomado para la realización de estos derechos

\subsubsection{La asimetría entre ambos pactos}

A simple vista se ven dos grandes diferencias: es mucho más largo el listado de derechos en el primer caso que en el segundo, que incluye, además, alguno ya sancionado en el primero; $y$ en el primero se establece la creación de un comité específico que audite el cumplimiento de los derechos humanos y en el segundo no, aunque ciertamente en 1985 se crea el Comité de Derechos Económicos, Sociales y Culturales ${ }^{3}$, resultado más bien de su reiterado incumplimiento. Pero la asimetría fundamental radica en que, así como el primer pacto establece en sus artículos 1.2 y 2.1 la obligación de los Estados parte de cubrir estos derechos con todos sus recursos disponibles, incluido el apoyo internacional necesario, así como tomar todas las medidas necesarias para su consecución real, en el Pacto de los Derechos Sociales en su artículo 2.1 expresa unas limitaciones de base: por un lado, somete tales derechos al principio de progresividad, cuya obligación mínima sería la no regresividad, y por otro, al llamado principio de reserva de lo posible. Ambos constituyen una cuestión recurrente en la discusión sobre el contenido y alcance de los derechos sociales, dando pie a la merma de estos derechos e incluso a su marginalidad (Hesse, 1978; Perlingeiro, 2014; Gargarella, 1998; Abramovich y Courtis, 2014). aspx.

2 https://www.ohchr.org/sp/professionalinterest/pages/cescr.

https://www.derechoshumanos.net/ONU/ComiteDerechosEconomicosSocialesCulturales-CESCR.htm.

\subsection{Derecho constitucional español}

La ley suprema de cualquier Estado moderno es la Constitución. Esta es el núcleo con el que ha de armonizar todo tratado, pero también toda normativa nacional por debajo de ella. Ciertamente, el artículo 96 de la Constitución Española (CE) reconoce que los tratados internacionales, una vez publicados en el Boletín Oficial del Estado, forman parte del ordenamiento interno; por su parte, el artículo 10.2 de la CE establece que los tratados sobre derechos humanos han de ser utilizados como criterio para la interpretación de las normas constitucionales en la materia.

A primera vista parece que está todo dicho. Pero se olvida que un tratado internacional ratificado por un Estado no consagra por sí mismo un derecho subjetivo a favor de los ciudadanos, sino solo un compromiso, a veces sometido a auditorías externas de control, si se firman los correspondientes protocolos facultativos, que raramente prevén un mecanismo judicial de tutela al alcance de los particulares (con la excepción notable del Convenio Europeo de Derechos Humanos), y menos aún un régimen sancionador.

Ello exige, en primer lugar, precisar mínimamente el concepto de derecho fundamental. Porque existe confusión en el uso de la expresión, incluso por parte del propio Tribunal Constitucional, que a veces lo usa en sentido restringido, referido a la Sección primera del Capítulo II del Título I de la Constitución (de los derechos fundamentales y de las libertades públicas), y otras en un sentido más amplio, comprensiva del todo el Capítulo II (Derechos y libertades) o incluso de todo el Título (De los derechos y deberes fundamentales). Pero hacerlo en un sentido u otro tiene sus consecuencias. A la luz del artículo 53 de la CE, nos encontramos en dicho título con tres niveles de protección:

a. Derechos garantizados al más alto nivel: los contenidos en la sección primera del Capítulo II de Título I (artículos 15 a 29), más los artículos 14 y 30.2 de la CE. Estos derechos son de aplicación directa, sin necesidad de desarrollo legislativo, al menos en su nivel esencial, y en su caso pueden ser garantizados mediante el recurso de amparo ante el Tribunal Constitucional. Esta protección del amparo no alcanza a los derechos contenidos en otras normas, especialmente en Tratados internacionales o en el derecho comunitario europeo.

b. Derechos garantizados a nivel medio: los pertenecientes a la sección segunda del mismo capítulo II (artículos 30 a 38), que no tienen las garantías anteriores, pero que sí están protegidos también por la reserva de ley: solo la ley puede regular su ejercicio y limitarlos, respetando en todo caso su contenido esencial.

c. Principios de política social y económica con protección mínima, en el Capítulo III del mismo Título I (De los principios rectores de la política social y económica) (artículos 39 a 52). Serán 
desarrollados por ley y solo pueden alegarse ante jurisdicción ordinaria según lo que dispongan estas leyes. Al no garantizarles el artículo $53.3 \mathrm{el}$ contenido esencial frente al legislador, no se los puede considerar derechos fundamentales.

Todo este engranaje jurídico nos viene a decir que siempre cabrá la posibilidad de interpretar un derecho a la baja, pues en el mejor de los casos se habla de mínimo esencial, abierto a la interpretación, en correlación directa con una política gubernamental de presupuestos, o que sea considerado como mero principio rector indicativo, que no se traduce en un derecho subjetivo exigible ante un juez.

Como hemos hecho con los pactos, vamos a exponer el listado de derechos contenido en cada uno de los grupos:

- En el primer grupo: no discriminación ante la ley; derecho a la vida y a la integridad física y moral; libertad ideológica, religiosa y de culto; derecho a la libertad y seguridad; derecho al honor y a la intimidad; derecho a elegir libremente residencia y movilidad; derecho a expresar y difundir sus pensamientos; derecho de reunión pacífica; derecho de asociación; derecho a participar en asuntos públicos; derecho a tutela efectiva de jueces y tribunales; nadie puede ser condenado por algo que cuando se hizo no era delito; se prohíben los tribunales de honor; derecho a la educación y pleno desarrollo de la personalidad; derecho de sindicación; derecho de petición individual.

- En el segundo grupo: obligación de contribución al gasto público; derecho a contraer matrimonio; derecho a la propiedad privada; derecho de fundación; deber y derecho al trabajo de libre elección; regulación por ley de colegios profesionales; derecho a la negociación colectiva entre trabajador y empresario; derecho de libertad de empresa.

- En el tercer grupo: seguridad, protección social, económica y jurídica de la familia; condiciones favorables para el progreso, estabilidad laboral en condiciones dignas; seguridad social ante las situaciones de necesidad; salvaguarda de los derechos de los trabajadores en el extranjero y política de retorno; protección de la salud pública; acceso a la cultura; medio ambiente adecuado al desarrollo personal, calidad de vida; promoción del patrimonio cultural; vivienda digna; participación de los jóvenes; previsión, tratamiento y rehabilitación e integración de los disminuidos físicos, sensoriales y psíquicos; pensiones adecuadas, actualizadas y suficientes, servicios sociales para sus problemas específicos de salud, vivienda, cultura y ocio; defensa de los consumidores; regulación democrática de las organizaciones profesionales.

Como vemos, en este último grupo no se habla de derechos, puesto que se trata de principios rectores y, por otro lado, al no garantizarles el artículo $53.3 \mathrm{el}$ mínimo esencial, no se pueden considerar derechos fundamentales. Pero es justo en este grupo donde se ubica la mayoría de derechos sociales reivindicados por la ciudadanía, siendo este un aspecto muy relevante a tener en cuenta, puesto que el Estado social se asienta sobre el derecho y la falta de garantías de los considerados derechos sociales ha ayudo en gran medida al decaimiento actual del Estado social y, en consecuencia, del Estado de Derecho democrático. Esto se predica de España, pero también de cualquier otro Estado social, incluidos aquellos más socialmente avanzados como pueden ser los países del centro y, sobre todo, del norte de Europa.

\section{Los derechos sociales}

El problema, sin embargo, no está solo en la identificación de un derecho fundamental, sino en las garantías con las que se le dota. Algunos autores denuncian en general la "ausencia de mecanismos de garantía de los derechos sociales" como "una omisión inconstitucional que el juez puede legítimamente colmar" (Escobar Roca, 2000: 534). Y en ese contexto se analiza también si la distinción entre unos derechos y otros en función de sus garantías se apoya en cierto concepto de subjetividad jurídica, que puede seguir primando el aspecto individual frente el aspecto colectivo, cuando en el sujeto coinciden necesariamente los dos elementos: el de sus propios intereses y el de la igualdad de todos, que hace inseparables los unos de los otros, adquiriendo pronto un carácter objetivo (De Cabo Martín, 2001: 122 y 125). López Pina (2002: 107) considera, en este sentido, que la Constitución:

[...] no se ha contentado con abrir la interpretación de los derechos a una dimensión institucional. Ha consagrado igualmente determinaciones específicas a la configuración jurídica de las instituciones en las que tales derechos desempeñan su función. Ese es el sentido que permite comprender unitariamente el complejo Capítulo III del Título I de la Constitución, que podría ser el eslabón jurídico-positivo que lograra la síntesis provisional, más acá de su contradicción de principio, entre lo objetivo y lo subjetivo, lo público y lo privado en nuestro Derecho constitucional ${ }^{4}$.

Esto entronca con una perspectiva histórica sin duda válida en el contexto del análisis teórico y crítico.

\footnotetext{
4 En esta línea se pronuncia Velasco Caballero (1995). Nótese que se habla de una "síntesis provisional", susceptible de ser reinterpretada o incluso reformada, por su funcionalidad como "principios rectores de la política social y económica”, en un nuevo contexto. En sentido similar, Gutiérrez Gutiérrez (2015: 372): “los principios rectores pueden ser comprendidos como determinaciones constitucionales relevantes para identificar el aspecto objetivo de los derechos fundamentales [...]. Los principios rectores expresarían el llamado deber de protección que vincula a los poderes públicos y les obliga a hacer frente a las distintas lesiones y amenazas".
} 
En efecto, los derechos fundamentales sirvieron inicialmente para defender la libertad privada, a cuya defensa se obligaba el Estado constitucional, limitando su intervención social a esta tarea; según Grimm (2006: 105-106), en el nuevo Estado social:

[...] los derechos fundamentales no están abocados al fracaso por una tendencia incorporada en favor de los intereses burgueses. Más bien su futuro depende de si el valor supremo al que dan expresión jurídica, la libertad individual igual, sigue siendo capaz de producir consenso. Libertad significa, a la vez, la preeminencia de la autodeterminación frente a la heteronomía, la posibilidad de proyectar un plan de vida propio, de establecer relaciones ventajosas, pero siempre con la reserva de un derecho igual para todos. De ahí se derivan necesariamente limitaciones a la libertad, aún mayores en una sociedad a la que el progreso científico-técnico hace cada vez más interdependiente y llena de riesgos. Sin embargo, el postulado de la libertad conserva la preeminencia, en tanto que todas las limitaciones se legitiman en dicho valor supremo y las condiciones para la realización de la libertad individual igual han de producirse conforme a ella [...]. La relevancia de los derechos fundamentales para la libertad está en que afianzan el nivel de prestaciones sociales que en el momento actual no podría mantenerse, habida cuenta de la limitada capacidad del Estado para gobernar mediante la dirección política. [...] Los derechos fundamentales actúan como señal de alarma, incorporada al orden jurídico, de los déficits de libertad del derecho válido y como principio dinámico del reajuste del derecho ${ }^{5}$.

En esta reflexión encontramos un fundamento válido de los derechos en la libertad, capaz de conciliar los llamados derechos individuales y sociales, que habrán de verse más como una evolución de estos en una sociedad de reconocimiento recíproco de derechos (Nino, 1989: 80) que en una relación de jerarquía o incluso de antagonismo. Hoy una respetable mayoría de autores se decanta por su armonización en las nuevas circunstancias históricas, pudiéndose generar nuevas facetas de los derechos individuales que pueden necesitar una mayor intervención del Estado para su efectividad (Corchete Martín, 2007; Barranco Avilés, 2001). También Abramovich y Courtis (2014) hablan de un continuum entre derechos y del complejo entramado de obligaciones positivas y negativas que todo derecho supone para el Estado.

${ }^{5}$ De especial interés es el concepto de "normas definidoras de tareas del Estado" (Staatszielbestimmuingen) de la Ley Fundamental alemana (Hesse, 2001: 97-100). Este concepto ayuda a clarificar: "La cláusula de Estado social de Derecho no fundamenta a priori pretensiones individuales directas de ningún tipo, aunque, entre otras cosas, puede ser de extraordinaria importancia para interpretar los derechos fundamentales que, como derechos derivados de participación, puedan justificar tales demandas".
Respecto al poder judicial, afirman estos autores que:

[...] por sus características institucionales y por el lugar que ocupa en la distribución de funciones dentro del Estado, no está llamado a ser el principal protagonista a la hora de hacer efectivos los derechos económicos, sociales y culturales, tarea que corresponde primariamente a los denominados poderes políticos. Sin embargo, si resulta provocado adecuadamente, puede ser un poderoso instrumento de formación y al mismo tiempo de desarticulación de algunas políticas públicas en el área social, con impacto directo en la vigencia de aquellos derechos. (Abramovich y Courtis, 2014: 118)

La jurisprudencia desarrolla así una importante labor en la concreción del contenido de los derechos, cuya vaguedad estimula a los interesados a expresar sus necesidades y al Estado a ir perfilando sus normativas en relación con ellas; los jueces examinan la idoneidad de las medidas públicas para hacerlas eficientes. Estos autores también indican la falta de tradición en el control judicial en este campo, que provoca en parte que los afectados recurran a otras estrategias de reclamo, como protestas y campañas de presión; pero consideran necesario aprovechar las vías de exigibilidad (directa o indirecta) que ofrece el derecho. Porque lo cierto es que hay diferentes niveles de garantía en la protección de los derechos. Se puede sostener que la garantía fundamental es la tutela jurisdiccional (Kelsen 1986: 148), pero el hecho de que no todos los derechos tengan tutela judicial igual (artículo 53 de la CE) no significa que no existan otros medios para atribuirles eficacia.

Como conclusión, cabe recordar que Escobar Roca (2012), en un importante estudio colectivo dirigido por él en defensa de los derechos sociales, habla de "derechos fundamentales sociales de prestación" (DFSP), resumiendo así en una sola expresión la construcción teórica de los derechos sociales y la problemática específica que plantea la tutela de los derechos de prestación. Quedan definidos como "aquellos derechos en que se concreta, mediante diversos tipos de prestaciones, la colaboración de los poderes públicos en la satisfacción de las necesidades básicas de los individuos" (Escobar Roca, 2000: 472). Y, respecto de sus garantías (Escobar Roca, 2012: 649-828; Ferrajoli, 2004), que se activan cuando alguien alega su incumplimiento, identifica seis categorías capaces de darles efectividad: Administración, jueces y tribunales, parlamento, defensor del pueblo, sociedad y órganos supranacionales. La garantía fundamental, en cualquier caso, sigue estando en la responsabilidad ciudadana, ya que:

[...] la exigibilidad de los derechos sociales como auténticos derechos indisponibles, y no como simples concesiones paternalistas y revocables, depende, más allá de las técnicas institucionales dispuestas para su protección, de la participación 
y la lucha de sus propios destinatarios. En los ordenamientos actuales [...] esa participación y esas luchas tienen lugar, de manera constante y muchas veces simultánea, en diversos niveles institucionales, pero también fuera de ellos y, no pocas veces, en su contra (Escobar Roca, 2012: 760).

\section{El decaimiento del Estado social como contexto global de nuestra Constitución}

Desde sus inicios, o antes al menos de llegar a su pleno desarrollo, el Estado social es considerado en crisis por muchos autores a causa de la contradicción entre el proceso de acumulación capitalista y el intento de redistribución por parte del derecho social. A fin de cuentas, los actuales Estados democráticos se asientan sobre antiguas estructuras de Estado; surgieron frente al Antiguo Régimen primero y frente al Estado liberal después tras la Revolución Industrial; sus estructuras han intentado adaptarse a los cambios, pero conservan inercias de desigualdad internas en virtud de su respeto al modelo económico capitalista. El Estado de Derecho se corresponde con la hegemonía del capitalismo; el Estado social, por su parte, garantiza la supervivencia de este frente al progreso del principio democrático, con una asimetría que se ha evidenciado progresivamente en un prolongado período de crisis que dura desde 1973 hasta nuestros días. La relativa bonanza del influjo keynesiano en la época de próspera recuperación tras el desastre bélico europeo llegó incluso a generar la ilusión de una especie de capitalismo popular y una supuesta socialización de la propiedad empresarial, creando la sensación mayoritaria de estar integrado en unas clases medias, cuyo valor distintivo es el consumo y no la antigua dignidad por el trabajo (López y Gutiérrez, 2002: 55-59; Teubner, 1987: 30-ss.).

Por otra parte, el principio democrático de soberanía popular sigue gozando de consenso a pesar de las asimetrías, y a su vez está íntimamente relacionado con la idea de representatividad, que ha ido evolucionado a la par con una sociedad beneficiada por un mayor acceso a la formación y a la información. Este cambio ha puesto de manifiesto la pluralidad social y la diversidad de intereses, que intenta armonizarse con la acción racionalizadora del Estado en un proceso descentralizador y participativo en las decisiones públicas. Esto supone una sociedad organizada que no necesariamente refleja de modo fiel la muy diversificada realidad, suponiendo un eventual riesgo de politización de la esfera social o la colonización por parte de intereses económicos organizados de corte neoliberal, que manipulan la opinión pública legitimadora (Porras Nadales, 1994: 89-90). Esto redunda en un discurso del malestar civil (Franzé, 1994) que se enfrenta a un Estado de partidos, cuya representatividad se considera insuficiente, y también a una gran parte de la sociedad satisfecha con su estatus que no desea implicarse en una tarea participativa global, a unas mayorías silenciosas que, aunque reciben los mensajes políticos a través de los poderosos medios de comunicación, no se sienten concernidas y carecen de representación formal, aunque después participen en las urnas en mayor o menor grado (Baudrillard, 1978) ${ }^{6}$.

En este sentido, Porras Nadales habla de procesos de microrepresentación en ámbitos limitados frente al monopolio de representación de los partidos en el ámbito estatal, configurando una esfera de gestión participativa en las políticas públicas. En ella los usuarios de servicios tienen una posición protagonista en el diseño y control de los diversos programas de intervención social, creando una vía consistente de solución a las exclusiones sociales: abrir vías de participación directa en la esfera de las decisiones públicas para llegar a políticas concretas. Se abre así la posibilidad de compromiso activo y sistematizado de los sectores afectados por cada tipo de acción pública, a la vez que surge un eficaz mecanismo de control preventivo y evaluativo, que dificultaría una posible desviación corrupta de las intervenciones sociales (Porras Nadales, 1994, 78; Beltrán Aguirre, 2005; Abramovich y Courtis, 2000). Esto ocurre porque la tendencia participativa democrática postula un derecho regulativo o postintervencionista que implique la incorporación al circuito político legitimador del proceso decisional micropolítico, dándole eficacia e incluso poder presupuestario: un nuevo derecho intervencionista con carácter receptivo que culmine un proceso decisional plural previamente desarrollado en el proceso político (Porras Nadales, 1994: 62-65 y 95-99; Majone y La Spina, 1993; Porras Nadales, 1989).

De este modo, el proceso democrático de representación entendería el bien común como una armonización de las aspiraciones de bienestar de todos los grupos sociales, teniendo en cuenta diferencias individuales o grupales que justifiquen una prioridad de atención (Subirats, 1992) y en general las cuestiones relativas a los llamados derechos sociales. Y, al mismo tiempo, los elementos tradicionales de control de lo público (el control jurisdiccional y político) se harían más completos, con un control evaluativo (accountability) que comprendería el control interno en el proceso, el control de los intereses externos, el control de resultados, la transparencia y la imputabilidad de responsabilidad pública (Porras Nadales, 1994: 110111; Sánchez Morón, 2008)7.

\footnotetext{
${ }^{6}$ Es interesante el enfoque de los "tres tercios", según el cual en Occidente un bloque de unos dos tercios tiene actitud conservadora ante el bienestar alcanzado, prefiriendo un confort inmediato sin sacrificios a largo plazo. Esto forma un bloque mayoritario políticamente insolidario con las desigualdades, impidiendo alternativas minoritarias, que quedan cada vez más excluidas. Esto explicaría un sistema representativo incapaz de reequilibrar el interés general a favor de todos los sectores (Galbraith, 1992).

7 En este contexto actúa, por ejemplo, la Dirección General de Ordenación de la Seguridad Social (DGOSS): “es un órgano directivo dependiente de la Secretaría de Estado de la Seguridad Social, al cual le corresponde entre otras el desarrollo de las funciones de ordenación
} 
Hoy es un hecho que, aunque las políticas sociales en estos campos pueden dejar bastante que desear, ningún partido político olvida en sus campañas electorales la referencia obligada a los colectivos menos favorecidos, puesto que su marginación resultaría políticamente incorrecta y restaría votos, no solo por parte de los pertenecientes a ellos, sino también por parte de las personas concienciadas en el derecho democrático de la igualdad, fruto de su labor reivindicativa en las últimas décadas. Una mayor participación activa de los grupos afectados sería sin duda una garantía de eficacia política a la vez que un potente signo de consenso y legitimación social en un Estado de Bienestar complejo, pero más avanzado democráticamente que el clásico bipartidismo, cuya legitimidad se cuestiona a tenor de un más evidenciado pluralismo social.

Una consecuencia de estos procesos socializadores podría sugerir la desregularización del sistema jurídico intervencionista, como podemos observar por ejemplo en España en el caos normativo de las distintas autonomías (pero también, en su caso, en los Estados federados) con respecto a las políticas sociales, cambiando ad hoc constantemente. Pero también hay que advertir que, según Maestro Buelga y García Herrera (1999: 65-67), esta dispersión autonómica no es algo inocente y azaroso, sino un deseo de descentralización intencionado desde el punto de vista del liberalismo económico adoptado por el Estado, que, en contradicción a la igualdad proclamada en su Constitución, que reclama una intervención (mínima) central, relega sin embargo a la periferia el grueso de las labores asistenciales desconectadas del mercado. De este modo, se produce una taimada asistencialización del Estado social, “en el que se adjudica como función básica del sistema de protección la intervención ante las situaciones de indigencia, despotenciando y perdiendo virtualidad el modelo constitucional de derechos sociales [...] la actividad asistencial recupera los rasgos propios del intervencionismo social en el liberalismo, en cuanto adopta cada vez más caracteres de prestación de control" (Maestro Buelga y García Herrera, 244-245).

Los más recientes procesos sociales y económicos de globalización, con importantes movimientos migratorios hacia los países desarrollados en busca de un Estado de Bienestar que no disfruta la inmensa mayoría de la humanidad, ponen sin embargo ante un nuevo peligro las bases del Estado social, centrado en una redistribución más solidaria de la riqueza en función de las necesidades personales o de colectivos específicos (De Vega,
1998; Parejo Alonso, 2000; Offe, 1984; Maestro Buelga, 2001). Hay que poner el centro de atención en las relaciones internacionales y en el desarrollo normativo que regula estas relaciones, entre ellas las de atención a las personas y colectivos más vulnerables, que implican la existencia de un Estado social y una aplicación real de políticas de bienestar consecuentes a sus principios. Aunque hoy por hoy estas políticas no han perdido su legitimidad, sí están en profunda revisión e incluso se confrontan con propuestas innovadoras que no habría que menospreciar (Felber, 2015; Rifkin, 2016). La globalización, y el desarrollo tecnológico que la ha hecho posible, ha cambiado las formas de ser ciudadano (García Canclini, 1995: 13), así como las estructuras sociales en las que se construye (González y Requena, 2012). Existen claras diferencias entre unos Estados y otros en cuanto al desarrollo de la democracia en general y sus implicaciones en un Estado social de Derecho. Este hecho afecta directamente a todo el Tercer Sector.

La Unión Europea, de la que España forma parte, no es ajena a este problema y, de un lado, promociona directrices apelando, por ejemplo, a la responsabilidad social de las empresas (Comisión Europea, 2011); pero, de otro, la globalización del mercado parece haber iniciado una tendencia al vaciamiento de los derechos sociales, auspiciada por la misma Unión Europea. Maestro Buelga (2017) habla de la "desconstitucionalización" de los Estados sociales, sobre todo a partir del panorama europeo que ha elevado la estabilidad presupuestaria a principio fundamental, tomando como base o como pretexto la globalización del mercado. La reforma de nuestro artículo 135 de la CE, en tensión con el postulado social del artículo 1.1, es un ejemplo cercano de una sociedad concebida como unión económica y monetaria que recoloca la propiedad como derecho central y acaba con la autonomía de los Estados mediante su coordinación macroeconómica. La reforma del mercado de trabajo y las políticas de austeridad propiciadas por esta "nueva" economía tienden a vaciar de contenido el Estado social. La “crisis fiscal del Estado" (O’Connor, 1979) ha dado finalmente al traste con el deseado Estado social y democrático de derecho, por la tendencia irreversible de los gastos estatales a crecer más rápidamente que los medios para financiarlos (Porras Nadales, 1988:49). La deuda colosal que todos los Estados mantienen hace que se haya priorizado una supuesta estabilidad económica sobre las necesidades sociales más perentorias. Acabar con esta contradicción sería la base para recuperar los derechos perdidos e incluso soñar con nuevos derechos para todos.

\section{Perspectivas en la reconstrucción del derecho social constitucional}

El derecho evoluciona con la sociedad y es preciso que ambos armonicen entre sí, si se quiere salir de esta larga agonía que ya dura tantos años. Es jurídica y económico-financieras de la Seguridad Social, planificación y realización de estudios económico-financieros y demográficos, elaboración del anteproyecto de presupuestos de la Seguridad Social, el seguimiento económico y presupuestario de las Entidades Gestoras y Servicios Comunes, conocimiento y evaluación de la gestión y situación económico-financiera de las Mutuas Colaboradoras con la Seguridad Social”. Consultar: 〈http://www.seg-social.es/Internet_1/ LaSeguridadSocial/Quienessomos/DireccionGeneralde029429/index.htm>. 
posible que asuste el gran calibre de los cambios que se intuyen necesarios, pero asusta mucho más el cruzarse de brazos y esperar a que la agonía resulte insoportable, sangrienta o mortal. Nosotros creemos necesario que se inicie un nuevo pacto ${ }^{8}$ que establezca las bases sólidas para reconducir a nuestro Estado a su labor social y democrática de derecho, que continúa vigente como desideratum, pero que ha fracasado estrepitosamente. Las bases de este nuevo pacto creemos que están disponibles en cuanto que se da un buen espíritu social participativo, con búsqueda de soluciones compartidas, más allá de las políticas de partido, que tendrán que esforzarse seriamente en dialogar con estas bases y entre ellos mismos, si quieren que su labor sea democráticamente productiva. Y esto es extensible a todos los Estados democráticos, puesto que todos caminamos en base a unos mismos principios y fines compartidos, salvando las peculiaridades nacionales, cada vez más difuminadas en un entramado universal.

Como arranque habría que empezar por reforzar los derechos hasta ahora reconocidos a nivel nacional, regional de naciones (como la Unión Europea) e internacionales (Naciones Unidas), reforzando igualmente las instituciones que las sustentan, dándoles un mayor poder normativo y sancionador. En este reforzamiento de derechos creemos que es imprescindible el reconocimiento de la igual importancia de todos los derechos, reclamando para ello los mismos recursos y los mismos esfuerzos estatales para que sean accesibles a todas las personas y colectivos. Tanta importancia tiene el derecho a la vida como el derecho a una vivienda y a un trabajo digno. Hoy no se pueden concebir unos derechos sin los otros, puesto que todos están interconectados, se influyen y son complementarios. Este es un trabajo esencial para un derecho que pretenda ser accesible a todos, también en su lenguaje, muchas veces intencionadamente incomprensible y confuso para la base social, que no llega a entender realmente a qué cosas tiene o no tiene derecho, o a saber por lo que tiene que luchar.

La división de los derechos entre políticos 0 sociales, individuales o colectivos, internacionales o nacionales, centrales o periféricos, etc., no ha hecho sino debilitar a una sociedad dividida, condenada a entenderse. Ciertamente, una visión igualitaria de los derechos conlleva un gran gasto social. Todos los derechos tienen un precio. Pero se trata de cambiar la visión de gastos en derechos, a inversión en derechos. Puesto que una sociedad que se siente mayoritariamente contenta con sus condiciones de vida va a ser mucho más productiva, renunciará a menos costes de oportunidad para dedicarse a lo que realmente quiere y tiene aptitudes, y se tendrían menos gastos inútiles provocados por las huelgas, manifestaciones, problemas de salud y suicidios, por poner algunos ejemplos.

La economía social hace mucho que está inventada (Rifkin, 2010), pero lo importante es llevarla eficazmente a la práctica. No hay que asustarse por los gastos. El sistema económico, el dinero y los impuestos equitativos son cosas inventadas por el hombre para nuestro bienestar y servicio, no para que nosotros vivamos en función de unos presupuestos que atienden a otros intereses individuales. Todos somos responsables de la construcción social; pero el derecho, sin duda, tiene un papel relevante en esa tarea, puesto que regula unas reglas de convivencia social universales. Nuestra Constitución, renovada en su sistematización de derechos y en el reparto actual de garantías a la luz de estos principios, podría ser un ejemplo a seguir por otros Estados en el camino de reconducir entre todos al derecho internacional hacia el fin social inicialmente marcado frente a las desigualdades entre personas y pueblos, con una mayor capacidad vinculante y sancionadora, que incite a un verdadero compromiso respetuoso con los pactos sociales logrados.

${ }^{8}$ En este sentido, intentamos colaborar mediante una página web nacida con vocación participativa y como foro de derecho social: 〈https://nuevopactosocial.org〉. 
ABRAMOVICH, V. y COURTIS, C. (2014): Los derechos sociales como derechos exigibles, Madrid, Trotta.

- (2000). "El acceso a la información como derecho", Anuario de Derecho a la Comunicación, vol. 1, nํㅜ 1, Buenos Aires, Siglo XXI.

BARRANCO AVILÉS, M.C. (2001): "El concepto republicano de libertad y el modelo constitucional de derechos fundamentales", Anuario de Filosofía del Derecho, nํㅜ 18, págs. 205-226.

BAUDRILLARD, J. (1978): A la sombra de las mayorías silenciosas, Barcelona, Kairós.

BELTRÁN AGUIRRE, J.L. (2005): “Los principios organizativos de la Administración social: descentralización, participación, coordinación y cooperación”, Documentación Administrativa, $\mathrm{n}$ - 271-272, págs. 207-236.

BOBBIO, N. (1991): El tiempo de los derechos, Madrid, Sistema.

COMISIÓN EUROPEA (2011): “Estrategia renovada de la UE para 2011-2014 sobre la responsabilidad social de las empresas", COM (2011) 681 final, Bruselas, 25-10-2011.

CORCHETE MARTÍN, M.J. (2007): "Los nuevos derechos", Teoría y realidad constitucional, $\mathrm{n}$ 을. págs. 535-556.

DE CABO MARTÍN, C. (2001): “El sujeto y sus derechos”, Teoría y Realidad Constitucional, nํㅜㄱ, págs. 117-136.

DE VEGA, P. (1998): “Mundialización y derecho constitucional: la crisis del principio democrático en el constitucionalismo actual", Revista de Estudios Políticos, nº 100, págs. 13-56.

DIRECCIÓN GENERAL DE ORDENACIÓN DE LA SEGURIDAD SOCIAL (2019): 〈http://www.seg-social.es/
Internet_1/LaSeguridadSocial/Quienessomos/ DireccionGeneralde029429/index.htm〉.

ESCOBAR ROCA, G. (2000): "Recensión: Luigi Ferrajoli, Derechos y garantías. La ley del más débil, Trotta, Madrid, 1999", en Derechos y libertades: Revista del Instituto Bartolomé de las Casas, Año 5, nํ9, págs. 521-534.

- (2012): "Los derechos fundamentales sociales de prestación (doctrina general)", en ESCOBAR ROCA, G. (dir.), Derechos sociales y tutela antidiscriminatoria, Thomson Reuters Aranzadi, págs. 459-647.

FELBER, C. (2015): Economía del Bien Común, Barcelona, Ediciones Deusto.

FERRAJOLI, L. (2004): Derechos y garantías. La ley del más débil, Madrid, Trotta.

FRANZÉ, J. (1994): “La sociedad civil frente a la crisis de la política. Control y desentimiento", Nueva sociedad, $\mathrm{n}-134$, págs. 102-117.

GALBRAITH, J.K. (1992): La cultura de la satisfacción, Barcelona, Ariel.

GARCÍA CANCLINI, N. (1995): Consumidores y Ciudadanos, México, Grijalbo.

GARGARELLA, R. (1998): “Primeros apuntes para una teoría sobre los derechos sociales. ¿Es posible justificar un tratamiento jurídico diferenciado para los derechos sociales e individuales?", Jueces para la democracia, nㅡ 31, págs. 11-15.

GONZÁLEZ, J.J. y REQUENA, M. (eds.) (2012): Tres décadas de cambio social en España, Madrid, Alianza Editorial.

GRIMM, D. (2006): Constitucionalismo y derechos fundamentales, Madrid, Trotta. 
GUTIÉRREZ GUTIÉRREZ, I. (2015): Elementos de Derecho constitucional español, Madrid, Marcial Pons.

HESSE, K. (1978): Grundzüge des Verfassungsrechts der Bundesrepublik Deutschland, HeidelbergKarlsruhe, C. F. Müller.

- (2001): "Significado de los derechos fundamentales", en BENDA, E. et al. (eds.), Manual de Derecho Constitucional, Madrid, Marcial Pons.

KELSEN, H. (1986): Teoría pura del Derecho, México, UNAM.

LÓPEZ PINA, A. y GUTIÉRREZ GUTIÉRREZ, I. (2002): Elementos de derecho público, Madrid/ Barcelona, Marcial Pons, Ediciones jurídicas y sociales.

MAESTRO BUELGA, G. (2001): "Globalización y constitución débil”, Teoría y Realidad Constitucional, $\mathrm{n}-7$, págs. 137-172.

- (2017): “El Estado Social, 40 años después: la desconstitucionalización del programa constitucional”, Revista de Derecho Político, no 100, págs. 766-798.

MAESTRO BUELGA, G. y GARCÍA HERRERA, M.A. (1999): Marginación, Estado Social y Prestaciones Autonómicas, Barcelona, Cedecs.

MAJONE, G. y LA SPINA, A. (1993): “El Estado regulador”, Gestión y Política Pública, vol. II, nº 2, págs. 197-261.

NINO, C.S. (1989): “La filosofía del control judicial de constitucionalidad", Revista del Centro de Estudios Constitucionales, no 4, págs. 79-84.

O'CONNOR, J. (1979): The Fiscal Crisis of the State, New York, St. Martin's Press.

OFFE, C. (1984): Contradictions of the Welfare State, London, Hutchinson.

PANITCH, L. (1999): “El nuevo estado imperial”, New Left Review, n을, pp. 5-18.

PAREJO ALFONSO, L.J. (2000): “El Estado social administrativo: algunas reflexiones sobre la «crisis» de las prestaciones y los servicios públicos", Revista de Administración Pública, no ${ }^{153}$, págs. 217-250.

PERLINGEIRO, R. (2014): “ ¿La reserva de lo posible se constituye en un límite a la intervención jurisdiccional en las políticas públicas sociales?", Estudios Socio-Jurídicos, vol. 16, nํㅡ 2, págs. 181-212.

PORRAS NADALES, A.J. (1994): Representación y democracia avanzada, Madrid, Centro de Estudios Constitucionales.

- (1989): "El derecho intervencionista del Estado. Aportaciones sobre un reciente debate", Revista de Estudios Políticos, no 63 , págs. 65-82.

- (1988): Introducción a una teoría del Estado postsocial, Barcelona, PPU.

RIFKIN, J. (2016): La sociedad de coste marginal cero: el internet de las cosas, el procomún colaborativo y el eclipse del capitalismo, Barcelona, Paidós.

- (2010): El fin del trabajo. Nuevas tecnologías contra puestos de trabajo: el nacimiento de una nueva era, Barcelona, Paidós.

SÁNCHEZ MORÓN, M. (2008): “Reflexiones sobre la participación del ciudadano en las funciones administrativas en el sistema constitucional español”, Revista catalana de dret públic, $\mathrm{n}-37$, págs. 223-245.

SUBIRATS, J. (1992): Análisis de políticas públicas y eficacia de la Administración, Madrid, Ministerio para las Administraciones Públicas.

TEUBNER, G. (1987): Juridification of Social Spheres. A comparative Analysis in the Areas of Labor, Corporate, Antitrust and Social Welfare Law, Berlin, Walter de Gruyter.

VELASCO CABALLERO, F. (1995): “La protección del medio ambiente ante el Tribunal Europeo de Derechos Humanos (Comentario a la Sentencia del Tribunal Europeo de Derechos Humanos en el caso ‘López Ostra contra España')”, Revista Española de Derecho Constitucional, Vol. 15, no 45 , págs. 305-324. 